\title{
PATIENTS WITH NEWLY DIAGNOSED DIABETES HAVE WORSE LONG-TERM OUTCOMES THAN KNOWN DIABETICS AFTER ST-SEGMENT ELEVATION MYOCARDIAL INFARCTION
}

Mahmoud Abdelnabi ${ }^{1}$, Abdallah Almaghraby ${ }^{2}$, Ola Abdelkarim ${ }^{2}$,Yehia Saleh ${ }^{3}$, Haitham Badran ${ }^{4}$

${ }^{1}$ Cardiology and Angiology Unit, Department of Clinical and Experimental Internal Medicine, Medical Research Institute, University of Alexandria, Egypt. ${ }^{2}$ Department of Cardiology, University of Alexandria, Egypt. ${ }^{3}$ Michigan State University, East Lansing, Michigan, United States of America.

\section{INTRODUCTION}

A significant portion of patients presenting with ST elevation

myocardial infarction (STEMI) are diagnosed incidentally with diabetes at the time of presentation. The effect of undiagnosed diabetes is thought to be comparable to known diabetics when it comes to long term outcomes.

\section{AIM OF THE WORK}

In this study we aimed to determine frequency of undiagnosed diabetic patients and their cardiovascular outcomes in comparison to those with known diabetes.

\section{PATIENTS \& METHODS}

1109 Patients presented with STEMI at 4 tertiary care centers in the period of January 2011 to December 2017. All patients eligible for the study were either diagnosed with diabetes mellitus (DM) previously or had a glycated hemoglobin $(\mathrm{HbA} 1 \mathrm{c})$ value of $6.5 \mathrm{~g} / \mathrm{dl}$ or more on presentation with the exclusion of non diabetic patients. We compared their in-hospital and 1-year outcomes and mortality (MACCE).

Table (1): Baseline characteristics

\begin{tabular}{|c|c|c|c|}
\hline $\begin{array}{c}\text { Total } \\
(n=1109)\end{array}$ & $\begin{array}{c}\text { Known DM } \\
(n=919)\end{array}$ & P value & $\begin{array}{c}\text { New DM } \\
(n=190)\end{array}$ \\
\hline Age & $51( \pm 6.9)$ & 0.9 & $50( \pm 9.1)$ \\
\hline Male Sex & $550(59.8 \%)$ & 0.71 & $124(65.3 \%)$ \\
\hline Hypertension & $535(58.2 \%)$ & 0.75 & $119(62.6 \%)$ \\
\hline Smoking & 492 (53.5\%) & 0.69 & $111(58.4 \%)$ \\
\hline Dyslipidemia & $101(11 \%)$ & 0.91 & $23(12.1 \%)$ \\
\hline HbA1C & $6.8( \pm 1)$ & $<0.001$ & $7.3( \pm 0.8)$ \\
\hline
\end{tabular}

Table (2): In-Hospital and 1 year MACCE

\begin{tabular}{|c|c|c|c|c|}
\hline \multicolumn{2}{|c|}{$\begin{array}{c}\text { Total } \\
(n=1109)\end{array}$} & $\begin{array}{c}\text { Known DM } \\
(n=919)\end{array}$ & P value & $\begin{array}{c}\text { New DM } \\
(n=190)\end{array}$ \\
\hline \multirow{5}{*}{$\begin{array}{c}\text { In-hospital } \\
\text { MACCE }\end{array}$} & Death & $41(4.5 \%)$ & 0.81 & $8(4.2 \%)$ \\
\hline & $\mathrm{MI}$ & 12 (1.3\%) & 0.73 & $2(1.1 \%)$ \\
\hline & TVR & $4(0.4 \%)$ & 0.9 & $1(0.5 \%)$ \\
\hline & CVA/TIA & $4(0.4 \%)$ & $<0.001$ & $0(0 \%)$ \\
\hline & MACCE & $61(6.6 \%)$ & 0.42 & $11(5.8 \%)$ \\
\hline \multirow{5}{*}{$\begin{array}{l}1 \text { Year } \\
\text { MACCE }\end{array}$} & Death & 63 (6.9\%) & 0.91 & $13(6.8 \%)$ \\
\hline & $\mathrm{MI}$ & 19 (2.1\%) & 0.74 & $7(3.7 \%)$ \\
\hline & TVR & $9(1 \%)$ & 0.005 & $6(3.2 \%)$ \\
\hline & CVA/TIA & $15(1.6 \%)$ & 0.02 & $4(2.1 \%)$ \\
\hline & MACCE & $106(11.5 \%)$ & 0.01 & $30(15.8 \%)$ \\
\hline
\end{tabular}

\section{RESULTS}

Of 1109 patients who were eligible, 919 (82.87\%) were known diabetics, $190 \quad(17.13 \%)$ were newly diagnosed diabetics. There was no significant difference in baseline data of both groups. However, newly diagnosed diabetes had a higher $\mathrm{HbA1c}$ in comparison to known diabetics (7.3 vs $6.8 \mathrm{~g} / \mathrm{dl})$.

In-hospital outcomes were similar in both groups regarding death, myocardial infarction and MACCE, however, the known diabetics group had a higher stroke rate $(0.04 \%$ vs $0 \%)$. For the 1 year follow up, the newly diagnosed diabetics group had a significantly higher MACCE rate.

\section{CONCLUSION}

In the setting of STEMI, newly diagnosed diabetics have comparable inhospital outcomes to patients with known diabetes. However, they have a higher MACCE in the one year follow up.

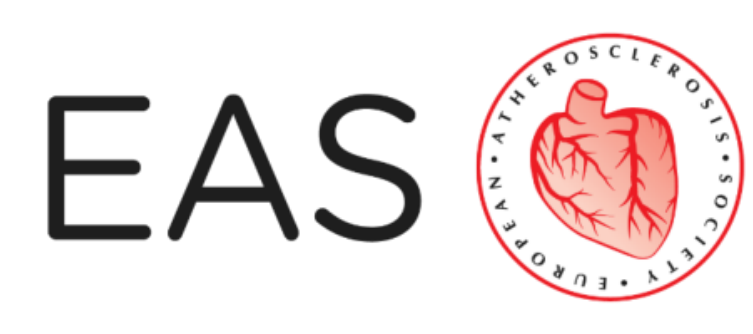

with thanks to the EAS for support in the form of a Young Investigator Fellowship 